\title{
Injury to a saphenous vein graft during removal of a temporary epicardial pacing wire electrode
}

\author{
COLIN PRICE, DANIEL J M KEENAN \\ From the Department of Cardiothoracic Surgery, Manchester Royal Infirmary, Manchester
}

SUMMARY Removal of a temporary atrial epicardial pacemaker electrode damaged a saphenous vein graft. A new blood clot was removed from the damaged graft. The hole was successfullig repaired with a polypropylene suture.

Pacing wires should be carefully sited and should be removed only when facilities for urgen operation are available.

\section{Case report}

A 64 year old man with unstable angina underwent urgent saphenous vein aortocoronary bypass grafting. Sequential atrioventricular pacing by temporary epicardial pacemaker electrodes was used to facilitate weaning from cardiopulmonary bypass but the operation was otherwise straightforward. His postoperative course was similarly uncomplicated until the removal of the pacing wires on the seventh day.

Both atrial electrodes were removed easily by gentle traction but he immediately felt unwell and was found to be hypotensive with a profound bradycardia. Fortunately, his ventricular wires were still in place and pacing was started, with initial recovery. Over the next two hours his blood pressure fell and an echocardiogram confirmed the presence of a haemopericardium.

He was transferred to the operating theatre and underwent urgent re-exploration. The right atrium was compressed by a new blood clot $(150 \mathrm{ml})$ originating from a tear in the saphenous vein graft to the right coronary artery. The haematoma was evacuated and, after systemic heparinisation, the graft was clamped and the hole was repaired with $7 / 0$ prolene suture. His further progress was uneventful and he was discharged seven days later.

\section{Discussion}

The placement of temporary epicardial pacemaker

Requests for reprints to Mr Colin Price, FRCS, Cardiac Surgery Unit, Manchester Royal Infirmary, Oxford Road, Manchester M13 9WL. electrodes is routine in cardiac surgical practice and many surgeons use both atrial and ventricular wires $\Phi_{\infty}^{\Phi}$ The improved haemodynamic effects of sequentiaf atrioventricular pacing and the potential for treating supraventricular arrhythmias with rapid atrial pacs ing are well recognised. ${ }^{2}$

We use a standard technique for fixing atria epicardial electrodes. A $1 \mathrm{~cm}$ loop of bare wire sutured high on the right atrial wall with a $6 / 8$ polypropylene (Prolene) and we prefer to site second similar atrial wire rather than an indifferent electrode. This has been shown to be more useful for diagnostic purposes and also causes less distortion of the electrocardiogram by the stimulus artefact during pacing. ${ }^{3}$ Several reports have emphasised the loy complication rate with this implantation technique and subsequent removal of the wires by gentle traction. ${ }^{34}$ Clinical and animal studies have not shown atrial bleeding to be an important problems and we can find no previous report of graft injur during removal of a pacing wire.

Most ventricular electrodes can be sited on the anterior surface of the right ventricle remote frong any grafts. Right atrial wires, however, often need careful positioning and this is a particular problem when two grafts are anastomosed proximally to the right aspect of the aorta.

Recognising the possibility of late injury, we novy try to site the electrodes where they can be remove without jeopardising a graft. We also believe that the timing of removal is important. Our policy is to. remove pacing wires early in the morning to permi observation throughout the day with optimum con $\oplus$ ditions for further investigation or operation. We never remove wires on the morning of discharge. 


\section{References}

1 Waldo AL, Henthorn RW, Plumb VJ. Temporary epicardial wire electrodes in the diagnosis and treatment of arrhythmias after open heart surgery. $\mathrm{Am} \mathrm{J}$ Surg 1984;148:275-83.

2 Friesen WG, Woodson RD, Ames AW, Herr RH, Starr A, Kassebaum DG. A haemodynamic comparison of atrial and ventricular pacing in postoperative cardiac surgical patients. J Thorac Cardiovasc Surg 1968;55: 271-9.

3 Waldo AL, MacLean WAH, Cooper TB, Kouchoukos
NT, Karp RB. Use of temporarily placed epicardial atrial wire electrodes for the diagnosis and treatment of cardiac arrhythmias following open heart surgery. J Thorac Cardiovasc Surg 1978;76:500-5.

4 Mills NL, Ochsner JL. Experience with atrial pacemaker wires implanted during cardiac operations. J.Thorac Cardiovasc Surg 1973;66:878-86.

5 Harris PD, Singer DH, Malm JR, Hoffman BF. Chronically implanted cardiac electrodes for diagnostic, therapeutic, and investigational use in man. $J$ Thorac Cardiovasc Surg 1967;54:191-8. 